\title{
Impact of sensitivity training on rural adolescents towards elders
}

\author{
SERENE SHEKHAR AND SARITA SANWAL
}

Received: 28.08.2014; Revised: 03.03.2015; Accepted: 13.03.2015

See end of the paper for authors' affiliations

\section{SERENE SHEKHAR}

Department of Extension and Communication Management, S.D. Agricultural University, S.K. NAGAR (GUJARAT) INDIA Email : shekhar.sdau@gmail.com
ABSTRACT : The study was undertaken under AGRESCO Project of Sardarkrushinagar Dantiwada Agricultural University of Gujarat state. The purpose of the study was to get insight of sensitive of today's generation about elderly and impact of training in bringing change in adolescent sensitivity. The result revealed that girls showed significant difference after training towards elder sensitivity in terms of providing nutrition, assisting in daily activity and providing health care to elders. Impact of training on boys' sensitivity towards providing nutrition to elders was found to be non-significant due to the fact that boys are rarely involved in food preparation activity. Personal variable like age and education showed positive and significant association with impact of sensitivity training towards elders among both girls and boys. Caste category, family type, family size, family income and occupation of the respondents had no significant association with sensitivity towards elders.

KEY WORDS: Sensitivity, Adolescent role, Elderly care

- HOW TO CITE THIS PAPER : Shekhar, Serene and Sanwal, Sarita (2015). Impact of sensitivity training on rural adolescents towards elders. Asian J. Home Sci., 10 (1) : 11-17. 